\title{
LA EXPANSIÓN DE LA HERMENÉUTICA FILOSÓFICA EN EL DERECHO*
}

\author{
Lenio Luiz Streck ** \\ UNISINOS-RS (Brasil)
}

RESUMEN. El giro hermenéutico-ontológico que se produjo en el siglo xx proporcionó un nuevo enfoque de la hermenéutica, ahora filosófica. A lo largo de este giro radical, podemos ver tres fases, a saber: la hermenéutica como una técnica especial de interpretación (hermenéutica especial), como una teoría general de la interpretación y como hermenéutica fundamental. Sin embargo, aún con todos los cambios que se producen dentro de una teoría crítica, con la superación de la hermenéutica clásica, todavía hay una gran resistencia a aceptar la recepción de la Hermenéutica Filosófica por el derecho de los campos tradicionales de pensamiento jurídico contemporáneo.

Palabras clave: derecho, hermenéutica filosófica, interpretación, comprensión, H.-G. GADAMER, M. HEIDEGGER.

ABSTRACT. The hermeneutic-ontological turn occurred in the twentieth century provided a new approach to hermeneutics, philosophical now. Across the times to the radicalization of this turn, we notice three phases in hermeneutics, namely: hermeneutics as a special technique of interpretation (special hermeneutics), as a general theory of interpretation, and as fundamental hermeneutics. However, even with all the changes that occur within a critical theory, with the overcoming of classical hermeneutics, there is still a great reluctance to accept the receipt of Philosophical Hermeneutics by the Law of the traditional fields of contemporary legal thinking.

Keywords: law, philosophical hermeneutics, interpretation, comprehension, H.-G. GADAMER, M. HEIDEGGER.

* Fecha de recepción: 10 de octubre de 2011. Fecha de aceptación: 13 de noviembre de 2011.

** Profesor titular de UNISINOS-RS; pos-doctor en derecho; lenio@unisinos.br. 


\section{INTRODUCCIÓN}

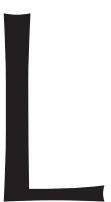

a palabra hermenéutica deriva del griego hermeneuein, y adquiere diversos significados en el curso de la historia. Esta busca traducir a un lenguaje accesible aquello que no es compresible. De ahí la idea de Hermes, un mensajero divino, que transmite - y, por tanto, esclarece- el contenido del mensaje de los dioses a los mortales. Al realizar la tarea de hermeneus, Hermes se torna poderoso. En realidad, nunca se supo lo que los dioses habían dicho; sólo lo que Hermes dijo acerca de lo que los dioses dijeron. Se trata, pues, de una (inter)mediación. De modo que, a menos que se crea en la posibilidad de acceso directo a las cosas (a la esencia de las cosas), es en la metáfora de Hermes donde radica toda la complejidad del problema hermenéutico. Se trata de traducir lenguajes y cosas atribuyéndoles un determinado sentido.

En la historia moderna, tanto en la hermenéutica teológica como en la hermenéutica jurídica, el concepto ha sido entendido como arte o técnica (método), con efecto directivo sobre la ley divina y la ley humana. El punto común entre la hermenéutica jurídica y la hermenéutica teológica reside en el hecho de que, en ambas, siempre hubo una tensión entre el texto propuesto y el sentido que alcanza su aplicación en la situación concreta, sea en un proceso judicial o en una plegaria religiosa. Esa tensión entre el texto y el sentido a serle atribuido, coloca a la hermenéutica frente a diversas opciones, todas ellas ligadas a las condiciones de acceso del hombre, al conocimiento acerca de las cosas. Así se demuestra que es posible establecer reglas que puedan servir de guía al hermeneuta en el acto interpretativo, mediante la creación, p. ej., de una teoría general de la interpretación; o se reconoce que la pretendida cesura entre el acto de conocimiento respecto del sentido de un texto y su aplicación a un determinado caso, no son de hecho actos diferentes, o se reconoce, finalmente, que las tentativas de situar el problema hermenéutico ya sea en la subjetividad del intérprete o en la objetividad del texto, no han pasado de ser contraposiciones fundadas en el metafísico esquema sujeto-objeto.

La crisis que atraviesa la hermenéutica jurídica tiene relación directa con la discusión, propia del inicio del siglo XX, acerca de la crisis del conocimiento y el problema de su fundamentación.

Muchas tentativas de establecer reglas o cánones para el proceso interpretativo a partir del predominio de la objetividad o de la subjetividad o de conjugar la subjetividad del intérprete con la objetividad del texto, no resistieron las tesis del giro linguístico-ontológico (HEIDEGGER-GADAMER), superadoras del esquema sujeto-objeto, comprendidas a partir del carácter ontológico previo del concepto de sujeto y de la desobjetivación provocada por el círculo hermenéutico y por la diferencia ontológica.

\section{EL MARCO QUE DEFINE LA RADICALIZACIÓN DE LA HERMENÉUTICA FILOSÓFICA: EL GIRO HERMENÉUTICO-ONTOLÓGICO}

El giro hermenéutico-ontológico, provocado por Sein und Zeit (1927), de M. HeIDEgGer, y la publicación, años después, de Wahrbeit und Methode (1960), por 
H.-G. GADAMER, fueron fundamentales para el surgimiento de un nuevo punto de vista sobre la hermenéutica jurídica. A partir de esa ontologische Wendung, se inició el proceso de superación de los paradigmas metafísicos objetivista aristotélico-tomista y subjetivista (filosofía de la conciencia) que hasta hoy sustentan, de una u otra forma, las tesis exegético-deductivistas-subsuntivas, predominantes en la llamada hermenéutica jurídica.

Antes de analizar sus consecuencias en el ámbito del pensamiento jurídico, conviene realizar una reflexión previa que permita identificar los caminos recorridos por la hermenéutica hasta la radicalización del giro hermenéutico-ontológico.

\subsection{La hermenéutica y sus tres etapas: técnica especial de naturaleza interpretativa, teoría general de la interpretación y hermenéutica fundamental}

Hermenéutica significa, tradicionalmente, teoría o arte de la interpretación y comprensión de textos, cuyo principal objetivo consiste en describir cómo se cumple el proceso interpretativo-comprensivo. En su sentido tradicional, la hermenéutica comporta, además de ese carácter teórico-descriptivo, una dimensión prescriptiva, en la medida en que, a partir de lo descriptivo, se intenta establecer un conjunto de reglas y métodos más o menos coherentes para interpretar y comprender correctamente los diversos textos que pueblan la escena cultural humana, sea en el ámbito del arte (literatura, poesía, etc.), sea en el ámbito religioso (interpretación de textos sagrados), sea en el ámbito jurídico (decretos, jurisprudencias, etc.). De tal modo, resultan así esbozados los ámbitos de conocimiento que habrán de interesarse, de manera más directa, por los problemas hermenéuticos: a) la Filología; b) la Teología, y c) el derecho.

En este punto inicial, es necesario atender un importante detalle: las reflexiones hermenéuticas siempre se desarrollan en una doble perspectiva. Hay una perspectiva teórica que procura describir cómo el proceso de interpretación y comprensión ocurre; qué tipo de conocimiento es ese; cómo ese conocimiento se articula en el interior de la dualidad que rige las teorías del conocimiento que oponen sujeto y objeto, en las que se afirma que en toda relación de conocimiento existe un sujeto que conoce y un objeto que es conocido, siendo el propósito de las teorías del conocimiento describir de qué modo esa oposición se resuelve en la mente, del sujeto que conoce. Esa sería una perspectiva teórica de la hermenéutica.

Por otro lado, existe también una perspectiva prescriptiva (práctica), en la medida en que esa descripción tiene como objetivo alcanzar un resultado: procura establecer reglas y métodos que conformen el proceso de interpretación y comprensión de modo que torne posible reducir los errores y malentendidos que puedan surgir de la lectura de los textos. Así, la hermenéutica no pretende solamente reunir un conjunto de conocimientos teóricos acerca del problema interpretativo-comprensivo, sino que en la línea del iluminismo-racionalista, pretende también generar criterios de certeza y objetividad a ser empleados en el proceso de interpretación y comprensión.

Las teorías clásicas de la hermenéutica operan, de una manera más o menos genérica, de la siguiente forma: primero se observan los problemas que emanan del proceso interpretativo, después se procura resolverlos a partir de la determinación de una 
estructura metodológica que reduzca errores e incomprensiones, posibilitando, así, la correcta comprensión de los textos analizados.

En el siglo XIX, con la emergencia de la discusión acerca de la autonomía de las ciencias humanas — también llamadas de Ciencias del Espíritu (Geisteswissenschaften)_, el filósofo alemán W. DiLTHEY habrá de emplear el término hermenéutica para designar la exploración y formación de la estructura metodológica de estas ciencias, basadas en un proceso de comprensión, mientras que las Ciencias Naturales - que recibieron su fundamento filosófico a partir de la Crítica de la Razón Pura, de KANTestarían basadas en procesos de explicación, desarrollados a través de una sistemática que implica causas y efectos.

Posteriormente, a partir de la primera mitad del siglo XX, principalmente a través de M. HEIDEGGER, el término hermenéutica se transforma y adquiere una connotación que nunca había sido pensada antes en toda la historia de la filosofía. Frente a este nuevo uso, al menos tres cuestiones de la doctrina clásica de la hermenéutica fueron puestas en cuestión: 1) su uso restringido a la interpretación de textos; 2) la prioridad de la interpretación sobre la comprensión, y 3 ) la estructura metodológica como garantía de certeza y objetividad del proceso interpretativo.

En efecto, HEIDEGGER radicaliza el problema hermenéutico al introducir en él, algo que podríamos llamar elemento antropológico. Por medio de sus intuiciones fundamentales el filósofo puede percibir que toda comprensión, sea ella comprensión de un texto o de la propia historia, se encuentra ya fundamentada en la comprensión que el ser humano tiene de sí mismo, en cuanto ser histórico dotado de existencia. De ese modo, todas las estructuras fundamentales de la existencia humana ${ }^{1}$ pasan a ser pen-

${ }^{1}$ Desde las Interpretaciones fenomenológicas sobre Aristóteles en 1921, pasando por el curso Ontología - Hermenéutica de la Facticidad en 1923, hasta llegar a su obra capital, Ser y Tiempo, en 1927, HeIDEGgER construye un concepto filosófico que produce una revolución en las teorías tradicionales de la subjetividad y de la conciencia. En efecto, el esfuerzo continuo del filosófo para poner la reflexión filosófica en los caminos de la vida fáctica — que, desde 1921 él ya llamaba facticidad — representó una ruptura con el carácter apodíctico que reviste el concepto de subjetividad desde DESCARTES, del mismo modo que rompía con las fundamentaciones empíricas del concepto de conciencia, que podemos observar en J. LOCKE. Ese concepto, que HeIDEGGER opondrá a toda la tradición filosófica anterior (Metafísica), es el concepto de Dasein (ser-ahí). Dasein será el término a partir del cual el filósofo designará - filosóficamente — al ser humano, a partir del cual serán analizadas las estructuras fácticas de la existencia humana. En la descripción realizada por el filósofo, Dasein es un tipo de ente que, en su modo de ser, posee como posibilidad la comprensión de su ser y del ser de los demás entes intramundanos. Dasein es, por tanto, el ente que comprende el ser y, en esta comprensión, tiene implícita una comprensión de su propio ser. El término alemán Dasein que tradicionalmente designa existencia (usado en este sentido por filósofos de la tradición metafísica, como es el caso de KANT, por ejemplo), encuentra serios problemas de traducción en otras lenguas. Esto porque HEIDEGGER atribuye al término una connotación diferenciada que mantiene el significado inicial de existencia, pero en el sentido de aquel ente que entre todos los otros existe, que es el ser humano. Para HeIDEgGER solamente Dasein existe, porque existencia implica posibilidades, proyectos. Los demás entes intramundanos, están a disposición, ellos subsisten. Esclareciendo la cuestión del Dasein, M. INWOOD afirma que: «Dasein es el modo de HeIDEGGER de referirse tanto al ser humano, cuanto al tipo de ser que los seres humanos tienen. Proviene del verbo Dasein que significa "existir" o "estar ahí, estar aquí", el sustantivo Dasein es usado por otros filósofos, KANT por ejemplo para designar la existencia de toda entidad. Pero HeIDEgGER lo restringe a los seres humanos [...] ¿Porque HeIDEgGer habla del ser humano de esta manera? El ser de los seres humanos es notablemente distinto de los seres de otras entidades del mundo. Dasein es una entidad por la cual, en su ser, este ser es una pregunta» (traducción libre del portugués al español; en portugués: «Dasein é o modo de HEIDEGGER referir-se tanto ao ser bumano quanto ao tipo de ser que os seres humanos têm. Vem do verbo dasein que significa "existir" ou "estar aí, estar aqui". O substantivo Dasein é usado por outros filósofos, KANT por exemplo para designar a existência de toda entidade. 
sadas y analizadas a partir de esta dimensión hermenéutica que fundamenta la propia existencia: comprendernos a nosotros mismos y a nuestra historia es condición de posibilidad para que podamos comprender textos, palabras, historias, etc. Por tanto: 1) del uso limitado a textos, la hermenéutica pasa a ocuparse de las estructuras fundamentales del ser humano; 2 ) interpretar un texto o una acción de otra persona, presupone una comprensión existencial de nosotros mismos; la prioridad de la interpretación cede lugar a la comprensión de modo que, no se interpreta para comprender, sino que se comprende para interpretar ${ }^{2}$, y 3 ) el necesario ideal de transparencia que se encontraba por detrás de las posturas hermenéuticas tradicionales y que posibilitaba la creencia de que sería factible encontrar un método rígido y definitivo para evitar errores y mal entendidos, desaparece en el interior de la hermenéutica heideggeriana desaparece. Y ello porque, por el propio hecho de la existencia el ser humano situado históricamente, se constituye en un elemento esencial para cualquier interpretación, no hay posibilidad de alcanzar ninguna transparencia. La facticidad humana siempre deja algo afuera (algo siempre escapa) lo que permanece posible es la tentativa de iluminar nuevos espacios de significado, y ello importa la necesidad de una pluralidad abarcadora de alternativas a seguirse, que el estrecho ideal moderno del método no posibilita ${ }^{3}$.

De manera general, quedan esbozados los tres momentos que atravesó la hermenéutica: de disciplina especial para la interpretación de textos (sacros, profanos y jurídicos) también llamada bermenéutica especial hacia una teoría general de la interpretación, con DiLTHEY y su proyecto de emancipación metodológica de las Ciencias del Espíritu; y por otra parte una hermenéutica fundamental, en cuanto reflexión incluida en las estructuras existenciales concretas de lo humano, tal cual lo describen HeIDEgGer y GADAmER. Procuraremos ahora abordar más de cerca cada uno de estos momentos.

\subsubsection{Hermenéutica especial}

Los estudios sobre hermenéutica no alcanzaban de una condición significativa antes de la eclosión del Humanismo Renacentista y de la Reforma Protestante. Solamente el uso canónico del término, en un sentido muy restringido a la exégesis de la Biblia, es que le otorgaba alguna dignidad durante la Edad Media. Pero la transición del Medievo a la Modernidad alteró ese panorama por dos razones: primero, en virtud del descubrimiento de los escritos profanos — prohibidos durante la Edad Media- y la necesidad de interpretación de estos escritos: segundo, en el contexto de la Reforma,

\footnotetext{
Mas HEIDEGGER restringe-o aos seres humanos. [...] Por que HEIDEGGER fala do ser humano dessa maneira? O ser dos seres bumanos é notadamente distinto dos ser de outras entidades do mundo. O Dasein é uma entidade para a qual, em seu Ser, esse Ser é uma questão»). Inwood, Michael Heidegger. Traducción de A. UbIRAJARA SobRaL, São Paulo, Loyola, 2004: 30-34.

2 STRECK, 2004: capítulo V.

3 Conviene registrar aquí una observación de H.-G. GADAMER cuando aborda la cuestión del método: «En verdad, la palabra método suena muy bien en griego, sin embargo, en cuanto una palabra extranjera moderna ella designa algo diverso, a saber, un instrumento para todo conocimiento tal como DESCARTES la denominó en su Discurso del Método. En cuanto término griego la palabra abarca la multiplicidad, con la cual se penetra en una región de objetos, por ejemplo, en cuanto matemático, en cuanto maestro de obras o en cuanto alguien que filosofa sobre ética».
} 
en virtud de la necesidad de buscar otra justificación para la interpretación de la Biblia que no estuviera reducida a la que provenía de la Iglesia de Roma.

GADAMER afirma que el primer registro de la palabra hermenéutica como título de libro remonta al año 1654, siendo atribuido al teólogo DANNHAUER. Fue él también quien probablemente sistematizó los estudios sobre hermenéutica y comenzó a hacer la distinción entre una hermenéutica teológica, una hermenéutica filológica y una hermenéutica jurídica ${ }^{4}$.

De una manera general, se puede decir que la hermenéutica teológica se ocupaba del arte de la interpretación de los textos sagrados; mientras que la hermenéutica filológica procuraba dar cuenta de la interpretación de las alegorías que aparecían en los textos de la literatura clásica. Los textos en griego exigían un esfuerzo muy grande para determinar los sentidos de las palabras, lo que inevitablemente llevaba a una interpretación de la etimología de cada uno de los vocablos empleados en las piezas clásicas. La hermenéutica jurídica, a su vez, procuraba dar cuenta de la interpretación de las compilaciones romanas. Era este el tiempo de la recepción y tenía todavía vigencia el derecho común, pre-codificado.

Esa fase marca en gran medida una configuración no unitaria de los estudios hermenéuticos, por eso se la denomina Hermenéutica especial, porque funcionaba como una disciplina especial para la interpretación de textos de cada uno de estos campos del conocimiento. GADAMER llama ese periodo hermenéutica clásica, y su importancia radica en que, ya en esa época, empiezan a aparecer los conceptos hermenéuticos fundamentales tales como: interpretación, comprensión y aplicación. También entonces surge una de las preocupaciones esenciales de la hermenéutica: la confrontación contra cualquier tipo de absolutismo dogmático.

\subsubsection{Teoría general de la interpretación}

Pero es con el romanticismo alemán que la hermenéutica asumirá sus contornos más sofisticados, llegando a ser tematizada expresamente como filosofía dotada de una universalidad. Nuevamente un teólogo, SCHLEIERMACHER, es quien efectuará esa tarea. La preocupación de SCHLEIERMACHER se refería a los problemas y los malentendidos que pudieran surgir en la comprensión de un texto. Malentendidos que llevarían a una interpretación completamente distinta del sentido que el autor del texto había procurado imprimirle. Era preciso entonces crear algo que permitiese que la interpretación preservase el sentido correcto, tal cual el autor lo prefigurara. Debido a su proximidad con la Ilustración alemana (Aufklärung), la propuesta de SCHLEIERMACHER se expresaba por vía del método. Pero el método de SCHLEIERMACHER era distinto de todos aquellos métodos que provenían de la tradición anterior. En parte, se trataba una continuidad del modelo circular ya conocido, a través del cual el intérprete se movería del todo hacia la parte y de la parte hacia el todo, a fin de avanzar en su comprensión con cada uno de los movimientos efectuados. Al final de este proceso, que SCHLEIERMACHER denominó Círculo Hermenéutico, el sentido original estaría preservado y la

\footnotetext{
4 GADAMER, 1986.
} 
comprensión encontraría en él aquello que el autor volcó en el texto. El énfasis en el «sentido del autor» llevará a los comentadores del mencionado filósofo a caracterizar su teoría de la interpretación como bermenéutica psicológica. La universalidad de la hermenéutica estaría garantizada por el método: se trataba de una universalidad procedimental ${ }^{5}$.

\subsubsection{Hermenéutica fundamental}

No es en este sentido que HeIDEGGER se apropia de la hermenéutica. La interpretación que propondrá es tan radical que el fondo metodológico que reviste el sentido tradicional de la hermenéutica quedará destruido. En un pequeño libro que corresponde a los inicios de la década de 1920 —en el cual el filósofo anticipa mucho de lo que será tratado más tarde en su obra máxima, Ser y Tiempo-, HeIDEGGER define un nuevo lugar para la hermenéutica y para el Círculo Hermenéutico de SCHLEIERMACHER. El nombre de la obra ya causa impacto; Hermenéutica de la Facticidad ${ }^{6}$.

A partir de este libro, la hermenéutica, hasta entonces utilizada exclusivamente para la interpretación de textos, pasa a tener por «objeto» otra cosa, la facticidad. ¿Pero qué es la facticidad? En una nota anterior, para explicar el giro ontológico de HEIDEGGER, afirmamos que el filósofo da al hombre el nombre de Ser-ahí y que el modo de ser de este ente es la existencia. Sin embargo, dijimos también que este ente - que somos nosotros- llamado Ser-abí, es lo que él ya fue, o sea: su pasado. Podemos decir que eso representa aquello que desde siempre nos atormenta y que está presente en las preguntas: ¿de dónde venimos?, ¿hacia dónde vamos?

La primera pregunta nos remite al pasado, la segunda, al futuro. El pasado es el marco histórico impreso en nuestro ser: Facticidad; el futuro es lo que tiene-que-ser, que caracteriza el modo-de-ser del ente que somos (Ser-ahî): Existencia. Por tanto, la hermenéutica es utilizada para comprender el ser (facticidad) del Ser-ahi y permitir la apertura del horizonte hacia el cual él se encamina (existencia). Aquello que tenía un carácter óntico, vuelto hacia textos, asume una dimensión ontológica, procurando la comprensión del ser del Ser-abí.

Adviértase: de un modo completamente innovador, HEIDEGGER coloca la reflexión filosófica en la concreción, en el plano práctico y precario de la existencia humana. Por

5 Para una amplia exploración histórica de la hermenéutica, reconstruyendo el camino de DiLTHEY desde la reafirmación de la hermenéutica en el ámbito de la filología y de la teología en el iluminismo alemán (Aufklanung) y de las contradicciones de la hermenéutica romántica, hasta su construcción como metodología de las ciencias del espíritu: GADAMER, 1999. Es importante resaltar que en el plano de la hermenéutica jurídica las conquistas de SCHLEIERMACHER permanecieron inexploradas durante mucho tiempo. Al contrario de las otras disciplinas hermenéuticas (teología y filología), el derecho permaneció recluído en los cánones tradicionales de la exégesis, que fueron constituidos en el interior de la interpretación de los textos romanos, recopilados por SAVIGNY en el seno del historicismo. Son por todos conocidos los tradicionales métodos de interpretación: gramatical, histórico, lógico-sistemático. Posteriormente, IHERING — para muchos el fundador intelectual de la llamada jurisprudencia de intereses - introdujo el método teleológico, tan preciado para la instrumentalidad del negocio. Es solo con el jurista italiano E. BETTI que el círculo hermenéutico de SCHLEIRMARCHER será introducido, procurando crear cánones específicos para el desarrollo de la interpretación jurídica. Para un contexto general de todo lo que fue dicho, vid. STRECK, 2009a.

${ }^{6}$ Heidegger, 1923. 
cierto que esa reflexión reclama una abstracción muy fuerte que resulta del distanciamiento necesario para percibir aquello que está más cerca nuestro. Sin embargo, la abstracción parte de algo concreto, fácticamente determinable y procura comprender aquello que nosotros mismos ya somos. Pero nosotros comprendemos lo que nosotros mismos ya somos, en la medida en que comprendemos el sentido del ser. También llamamos la atención respecto del hecho de que el hombre (Ser-ahî) y ser, están unidos por un vínculo indisociable.

Esto porque, en todo aquello con lo que él se relaciona, el hombre ya comprendió su ser, aun cuando él no lo advierta. Hay, en toda acción humana, una comprensión anticipadora del ser, que permite que el hombre se mueva en el mundo más allá de un actuar en el universo meramente empírico, ligado a los objetos. No nos relacionamos con las cosas, esto es, con lo empírico, porque de algún modo ya sabemos lo que ellas son. Hay algo que ocurre, más allá de la pura relación objetivante ${ }^{7}$. Nuestro privilegio se constituye por el hecho de que tenemos la «memoria del ser»; o sea: tenemos un privilegio óntico - entre todos los entes, solo nosotros existimos-; y un privilegio ontológico, porque de todos los entes somos los únicos que, en su modo-de-ser comprenden el ser. De ese doble privilegio, el filósofo percibe un tercero: un privilegio óntico-ontológico, la comprensión del ser de este ente que somos, es la condición de posibilidad de todas las otras ontologías (del derecho, de la historia, del proceso, etc.) ${ }^{8}$.

Didácticamente, podemos decir: el hecho de afirmar que algo es, ya presupone que tengamos de ese algo una comprensión, aun cuando sea incierta y mediana. ¡Y más! Sólo nos relacionamos con algo, actuamos, direccionamos nuestras vidas, en la medida en que tenemos una comprensión del ser. Al mismo tiempo, sólo podemos comprender el ser en la medida en que ya nos comprendemos en nuestra facticidad. El seguimiento de esta rápida exposición, por sí solo, da cuenta ya de la estructura circular en que se mueve el pensamiento heideggeriano. Esa estructura circular es el Círculo Hermenéutico, no ligado más a la interpretación de los textos, sino a la comprensión de la facticidad y existencia del Ser-ahí ${ }^{9}$. Es preciso advertir que el hombre sólo comprende el ser en la medida en que pregunta por el ente. Veamos nuestro caso: colocamos en movimiento una reflexión sobre el proceso en la perspectiva de que, al final, podamos decir algo sobre su ser (una definición sobre el proceso comenzaría: el proceso es...).

\footnotetext{
7 Para un análisis pormenorizado: STEIN, 2002.

8 Heidegger, 2005: 36.

9 Sobre el circulo hermenéutico en el sentido que asume en HeIDEGgER, STEIN anota lo siguiente: «El hombre se comprende cuando comprende el ser, para comprender el ser. Mas luego enseguida HEIDEGGER va a decir: "No se comprende el hombre sin comprenderse el ser". Entonces la ontología fundamental se caracteriza por ese círculo: se estudia aquel ente que tiene por tarea comprender el ser $\mathrm{y}$, con todo para estudiar ese ente que comprende el ser, es preciso ya tener comprendido el ser. El ente hombre no se comprende a sí mismo, sin comprender el ser, y no comprende el ser sin comprenderse a sí mismo; eso en una especie de esfera antipredicativa que sería el objeto de la exploración fenomenológica — de ahí viene la idea de circulo hermenéutico en el sentido más profundo—》 (traducción libre del portugués al español; en portugués: «O homem se compreende quando compreende o ser, para compreender o ser. Mas logo em seguida HEIDEGGER vai dizer: "Não se compreende o homem sem se compreender o ser". Então a ontologia fundamental é caracterizada por esse círculo: estuda-se aquele ente que tem por tarefa compreender o ser e, contudo, para estudar esse ente que compreende o ser, já é preciso ter compreendido o ser. O ente homem não se compreende a si mesmo sem compreender o ser, e não compreende o ser sem compreender-se a si mesmo; isso numa espécie de esfera antepredicativa que seria o objeto da exploração fenomenológica - daí vem a idéia de círculo bermenêutico, no sentido mais profundo»). STEIN, 2008: 79.
} 
Pero nadie negaría que el proceso es un ente. Un ente que es interrogado en su ser, pues toda pregunta por el proceso depende de eso. ¿Qué es el proceso? ¿Cómo es el proceso? Así, aunque el ser y el ente se den en una unidad que es la comprensión que el hombre (Ser-ahi) tiene del ser, hay entre ellos una diferencia. Esa diferencia es denominada por HEIDEGGER diferencia ontológica y se da por el hecho de que todo ente sólo es en su ser. En otras palabras, la pregunta se dirige hacia el ente, en la perspectiva de comprenderlo en su ser.

Hablamos del Círculo Hermenéutico y de la diferencia ontológica. Que son los dos teoremas fundamentales de la fenomenología hermenéutica. Sabemos, entonces, que el hombre (Ser-ahî) se comprende a sí mismo y comprende el ser (Círculo hermenéutico), en la medida en que pregunta por los entes en su ser (diferencia ontológica).

Así, el fenómeno que aquí se enfatiza es la comprensión. A partir de HeIDEgGER, la hermenéutica tendrá raíces existenciales porque se dirige hacia la comprensión del serde-los-entes. Si en los paradigmas anteriores, regía la creencia de que primero interpretamos - a través de un método- para luego comprender, HEIDEGGER nos muestra, a partir de la descripción fenomenológica realizada por la analítica existencial en Ser y Tiempo, que comprendemos para interpretar ${ }^{10}$. La interpretación es siempre derivada de la comprensión que tenemos del ser de los entes. O sea, originariamente el Ser-abí comprende el ente en su ser y, de una forma derivada, vuelve explícita esa comprensión a través de la interpretación. En la interpretación, procuramos manifestar ónticamente aquello que fue resultado de una comprensión ontológica. La interpretación es el momento discursivo-argumentativo en que hablamos de los entes (proceso, derecho, etc.) por la comprensión que tenemos de su ser ${ }^{11}$.

$\mathrm{Y}$, como desde siempre comprendemos el ser, no hay un puente entre conciencia y mundo. Aquello que era reivindicado por KANT fue desmitificado por HEIDEGGER en el momento en que el filósofo descubrió el vínculo entre hombre y ser. No hay un puente entre conciencia y mundo, porque desde siempre ya estamos en el mundo comprendiendo el ser. O sea, hay un vinculo entre ser-ahí-ser y una cooriginariedad entre ser y mundo. No hay primero el Ser-ahí y después el mundo o viceversa. El Ser-abí es ser-en-el-mundo y su facticidad es estar-jugado-en el mundo; su existencia es tenerque-ser-en-el-mundo, siendo que, desde siempre, está junto a los entes ${ }^{12}$.

10 STRECK, 2004: 197 y ss.

11 Así habla HeIDEGGER: «En la interpretación el comprender se apropia comprensivamente de lo comprendido por él. En la interpretación el comprender no se convierte en otra cosa, sino que llega al ser él mismo. La interpretación se funda existencialmente en el comprender, y no es este el que llega a ser, por medio aquella. La interpretación no consiste en tomar conocimiento de lo comprendido, sino en la elaboración de las posibilidades proyectadas en el comprender» (Ser y Tiempo, trad. de J. E. RIVERA, 4. ${ }^{a}$ ed., Santiago, Editorial Universitaria, 2005: 172).

12 La idea heideggeriana de ser-en-el-mundo es de fundamental importancia para comprender la ruptura definitiva que el filosofo efectúa con relación a los dualismos de la tradición metafísica (p. ej., conciencia y mundo, palabras y cosas, conceptos y objetos, etc.). Como afirma HEIDEGGER: «El Dasein no es primero sólo un ser-con-otro, para luego, a partir de ser en convivencia, llegar a un mundo objetivo, a las cosas. Este punto de partida sería tan erróneo como el del idealismo subjetivista que antepone primero un sujeto que luego, en cierto modo crea un objeto. [...] El Dasein no está delante de las cosas como un ente que posee su propio modo de ser, sino que el Dasein, en tanto que ente, que se ocupa de sí mismo, es co-originariamente ser-con-otro y ser cabe el ente intramundano. [...] Sólo si hay Dasein, si el Dasein existe como ser-en el-mundo, hay comprensión del ser, y solo si existe esta comprensión se devela el ente intramundano como lo subsistente y lo que está a la mano. La comprensión del mundo en tanto que comprensión del Dasein es comprensión de sí mismo. El yo y el 
Hay otras peculiaridades que podríamos explorar en la transformación que se opera en la Filosofía con el pensamiento heideggeriano. A efectos de esta investigación, nos damos por satisfechos con la comprensión de que la hermenéutica recibe, a partir de entonces, un nuevo tratamiento, siendo colocada al nivel del mundo práctico. Lo que precisa quedar establecido es que el hombre (Dasein) se presenta en el centro del mundo, reuniendo los hilos de este mundo. Al escoger al hombre (Dasein) como punto central de su filosofía, HEIDEGGER no se concentra en un ente con exclusión de otros; el Dasein trae consigo el mundo entero ${ }^{13}$. Eso es así porque el Dasein es desde siempre ser-en-el-mundo; porque su condición es, comprendiéndose a sí mismo, la comprensión del ser (Círculo Hermenéutico); y comprende el ser a través de la pregunta por el ente (diferencia ontológica).

Captar las estructuras de comprensión (que como vimos siempre es histórica) no es posible por la vía del método, una vez que, como elemento interpretativo, el método siempre llega tarde. Lo que organiza el pensamiento y comanda la comprensión no es una estructura metodológica rígida - como creía SCHLEIERMACHER—, sino la diferencia ontológica. Todas esas conquistas heideggerianas serán recogidas después por otro hermeneuta, GADAMER, que encontrará espacio para la construcción de su hermenéutica filosófica. El título de su obra principal es Verdad y método, pero bien podría llamarse Verdad contra el método o Verdad a pesar del método, a partir de lo cual la hermenéutica se radicaliza como un actuar mediador a través de la experiencia, del arte, de la historia y del lenguaje ${ }^{14}$.

\section{LA HERMENÉUTICA JURÍDICA ANTE ESA INTRINCADA TESITURA}

En la doctrina y en la jurisprudencia del derecho todavía resulta dominante la idea de que es indispensable el método o algún procedimiento capaz de alcanzar la «voluntad de la norma», el «espíritu del legislador» la correcta interpretación del texto, etc. Se cree que el acto interpretativo es un acto cognitivo y que «interpretar» la ley es extraer de la norma todo lo que ella contiene, circunstancia que denuncia a las claras, la problemática metafísica implicada en ese campo de conocimiento.

La hermenéutica jurídica practicada en el plano de la cotidianeidad del derecho, echa raíces en la discusión que llevó a GADAMER a hacer la crítica del proceso interpretativo clásico, que entendía la interpretación como el producto de una operación realizada por partes (subtilitas intelligendi, subtilitas explicandi, subtilitas applicandi, esto es, primero comprendo, después interpreto, para sólo entonces aplicar). La imposibilidad de esa censura, supone la imposibilidad de que el intérprete «extraiga» del texto «algo que el texto posee-en-sí-mismo», en una especie de Auslegung, como si fuese posible reproducir sentidos. Al contrario, para GADAMER, fundado en la hermenéutica filosófica, el intérprete siempre atribuye sentido (Sinngebung). El acontecer

mundo se coopertenecen mutuamente en un único ente, el Dasein. Yo y mundo no son dos entes, como sujeto y objeto, tampoco como yo y tú más bien, yo y mundo son, en la unidad de la estructura del ser-en el-mundo las condiciones fundamentales del propio Dasein» (Los problemas fundamentales de la fenomenología, trad. de J. J. García Norro, Madrid, Trotta, 2000: 354-355).

13 InWOOD, Heidegger, op. cit., 33.

14 GADAMER, 1999. 
de la interpretación ocurre a partir de una fusión de horizontes (Horizontenverschmelzung), porque comprender es siempre el proceso de fusión de ciertos horizontes sobre sí mismos.

Algunas posturas críticas sobre la hermenéutica jurídica —en especial la hermenéutica filosófica de H.-G. GADAMER - recibieron una nítida influencia de la ontología fundamental de matriz heideggeriana, a partir de sus dos principales teoremas: el círculo hermenéutico y la diferencia ontológica. Para interpretar, necesitamos comprender; para comprender, necesitamos tener una precomprensión, constituida como estructura previa del sentido - que se funda, esencialmente, en una posición previa (Vorbabe), visión previa (Vorshicht) y concepción previa (Vorgriff)— que ya une todas las partes del «sistema».

Tenemos una estructura de nuestro modo de ser en el mundo, que es la interpretación. Estamos condenados a interpretar. El horizonte de sentido nos es dado por la comprensión que tenemos de algo. Comprender es un existencial, una categoría por la cual el hombre se constituye. La facticidad, la posibilidad y la comprensión son algunos de esos existenciales. Es en nuestro modo de comprensión en cuanto ser en el mundo, que surgirá la «norma» como producto de la «síntesis hermenéutica» que se da a partir de la facticidad y la historicidad del intérprete.

De cualquier forma, todo lo que ha sido descrito aquí, apunta al siglo XX como la verdadera «era de la hermenéutica». Esa era, fundamenta la tesis de que la Teoría del derecho, durante el siglo XX, efectúa una especie de recepción de estas tres revoluciones descriptas precedentemente (del lenguaje, del fundamento y de la ontología), encontrando su punto culminante en la filosofía hermenéutica de HEIDEGGER y en la hermenéutica filosófica de GADAMER. Esta recepción es percibida en diferentes grados por diversos autores. Pero, de una forma global, en todos ellos es posible percibir lo que J. LAMEGO llama «acceso hermenéutico al derecho».

En lo que toca a la fenomenología hermenéutica —entendida globalmente, incluyendo los descubrimientos tanto de HEIDEGGER cuanto de GADAMER-, es posible percibir en las obras de J. EsSER, F. MÜLLER, A. KAUfMAnn y R. DwOrKInN ${ }^{15}$ la recepción de los principales conceptos desenvueltos por esta tradición hermenéutica del siglo XX. En todos estos autores existe la posibilidad de pensar en un acceso bermenéutico al derecho.

\subsection{La superación de la hermenéutica clásica y las posibilidades de recepción de la hermenéutica filosófica por el derecho}

La superación de la hermenéutica clásica —o de aquello que ha sido denominado hermenéutica jurídica, como técnica en el seno de la doctrina y de la jurisprudencia practicadas cotidianamente-, implica admitir que hay una diferencia entre el texto jurídico y el sentido de ese texto, esto es, que el texto no «carga», de forma reificada,

15 En el contexto del derecho brasileño también, mis obras presentan esta «recepción» de la hermenéutica por la teoría del derecho [Hermenêutica Jurídica e $(m)$ Crise, op. cit., y Verdad y Consenso, Lima, ARA, 2009]. En cuanto a los otros autores citados en el texto, es importante ver: DwORKIN, 2000, 1985, 1997; KAUFMANN, 1999; MülleR, 1995, 1975, 2006; LAMEgO, 1990; EsSER, 1961. 
su sentido (su norma). Se trata de entender que entre texto y norma no hay una equivalencia y tampoco una total autonomía. Entre texto y norma sí hay una diferencia, que es ontológica, porque - y aquí la importancia de los dos teoremas fundamentales de la hermenéutica jurídica de carácter filosófico- el ser es siempre el ser de un ente y el ente sólo es en su ser. El ser existe para dar sentido a los entes. Por esto hay una diferencia ontológica (no ontológico-esencialista) entre ser y ente, tesis que ingresa en el plano de la hermenéutica jurídica para superar, tanto el problema de la equiparación entre vigencia y validez, como el de la total separación entre texto y norma, resquicios de un positivismo jurídico que convive con una total discrecionalidad en el acto interpretativo.

Mientras tanto, la afirmación de que el «intérprete siempre atribuye sentido (Sinngebung) al texto» ni de lejos puede significar autorización para atribuir sentidos a los textos en forma arbitraria, como si el texto y la norma estuviesen separados (y, por tanto, tuviesen «existencia» autónoma). Como acertadamente dice GADAMER, cuando el juez adecua la ley a las necesidades del presente, tiene claramente la intención de resolver una tarea práctica (vid. aquí, la importancia que GADAMER da al programa aristotélico de una praktishe Wissenschaff). Esto no quiere decir, de modo alguno, que su interpretación de la ley sea una traducción arbitraria.

Por tanto, resultan rechazadas todas las formas de decisionismo y discrecionalidad. El hecho de que no exista un método que pueda dar garantía de «corrección» al proceso interpretativo, denuncia presente ya en el octavo capítulo de la Teoría Pura del Derecho de H. KELSEN, no autoriza al intérprete a escoger el sentido que más le convenga, lo que sería poner en práctica la discrecionalidad típica del convencionalismo exegético-positivista. Sin textos, no hay normas. La «voluntad» y el «conocimiento» del intérprete no permiten la atribución arbitraria de sentidos y tampoco una atribución de sentidos arbitraria. Al final, y la lección esta expresada en Wabrheit und Metho$d e$, si quieres decir algo sobre un texto, deja que el texto te diga algo.

La hermenéutica jamás habilitó ninguna forma de «decisionismo»o «realismo». GADAMER rechaza de plano cualquier acusación de relativismo como proveniente de la hermenéutica jurídica. Hablar de relativismo es admitir verdades absolutas, problemática en verdad jamás demostrada. La hermenéutica aparta el fantasma del relativismo, porque este niega la finitud y secuestra la temporalidad.

Una hermenéutica jurídica que se pretenda critica, hoy debe, fundamentada en esa revolución copernicana, procurar corregir el equívoco de las teorías de la interpretación, que, aunque reconozcan que el derecho se caracteriza por un proceso de aplicación a casos particulares (concreción), incurren en el paradigma metafísico, al elaborar un proceso de subsunción a partir de conceptualizaciones (vid. el paradigmático caso de las súmulas vinculantes ${ }^{16}$ en Brasil), que se transforman en «significantes-primordiales-fundantes» o «universales jurídicos», «acoplables» a un determinado «caso jurídico». Esto ocurre de las más variadas formas en el modus interpretativo vigente en la doctrina y la jurisprudencia, como el establecimiento de topoi o de meta-criterios

${ }_{16}$ Súmula es la consolidación de la jurisprudencia, equivaliendo, salvadas las especificidades de los sistemas jurídicos, a los precedentes del common law. Con la alteración de la Constitución de Brasil en el 2004, las Súmulas del Supremo Tribunal Federal en materia constitucional pasaron a ser Súmulas Vinculantes. En síntesis, las súmulas «positivan» la jurisprudencia dominante. 
para la resolución de conflictos entre principios, más allá de las fórmulas que reglan la interpretación, propuestas por las diversas teorías de la argumentación jurídica.

No es suficiente decir, pues, que el derecho es concreción, y que «cada caso es un caso», como es común en el lenguaje de los juristas. Finalmente, es más que evidente que el derecho es concreción y que es hecho para resolver casos particulares. Lo que no es evidente es que el proceso interpretativo es applicatio, entendida en el sentido de búsqueda de la cosa misma (Sache selbst), esto es, en el sentido de no olvidar la diferencia ontológica. El derecho es parte integrante del propio caso y una cuestión de hecho es siempre una cuestión de derecho y viceversa. La hermenéutica no es filología. Es imposible escindir la comprensión de la aplicación. Una cosa es «deducir» de un topos o de una ley el caso concreto; otra es entender el derecho como aplicación: en la primera hipótesis, se estaría entificando el ser; en la segunda, se está realizando la aplicación de índole hermenéutica, a partir de la idea de que el ser es siempre ser-en (in Sein).

Así, aunque los juristas —en sus diferentes filiaciones teóricas- insistan en decir que la interpretación debe darse siempre en «cada caso», tales afirmaciones no encuentran comprobación en la cotidianeidad de las prácticas jurídicas. En verdad, al construir «pautas generales», «conceptos lexicográficos, artículos doctrinarios y jurisprudenciales» o súmulas aptas para «resolver» casos futuros, los juristas sacrifican la singularidad del caso concreto, en favor de esas especies de «pautas generales», fenómeno, sin embargo, que no es percibido en el imaginario jurídico. ¿De ahí la indagación de GADAMER: existiría una realidad que permita buscar con seguridad el conocimiento del universival, de la ley, de la regla, y que encuentre ahí su realización? ¿No es la propia realidad el resultado de su interpretación?

El rechazo de cualquier posibilidad de subsunciones o deducciones, apunta hacia el propio núcleo de una hermenéutica jurídica inserta en los marcos del pensamiento pos-metafísico. Se trata de superar la problemática de los métodos, considerados por el pensamiento exegético-positivista como puertos seguros para la atribución sentidos. Comprender no es el producto de un procedimiento (método) y no es tampoco un modo de conocer. Comprender es, sí, un modo de ser, porque la epistemología es sustituida por la ontología de la comprensión. Esto significa romper con las diversas concepciones que se formaron a la sombra de la hermenéutica tradicional, de cuño objetivista-reproductivo, cuya preocupación es de carácter epistemológico-metodológico-procedimental, escindiendo conocimiento y acción, en la búsqueda de garantizar la «objetividad» en los resultados de la interpretación. La misma crítica puede ser hecha a la tópica retórica, cuya dinámica no escapa de las trampas de la subsunción metafísica. Por otra parte, el hecho de vincularse «al problema» no saca de la tópica, su dependencia respecto de la deducción y de la metodología tradicional, lo que resulta fundamentalmente de su carácter no filosófico.

\subsection{Dificultades de aceptación de la recepción de las tesis de la hermenéutica filosófica por parte de los sectores tradicionales del pensamiento jurídico}

A pesar de la revolución copernicana producida por la revuelta lingüístico-hermenéutica, es posible detectar nítidamente su no recepción por la hermenéutica jurídica 
practicada en las escuelas de derecho y en los tribunales, donde todavía predomina el método, aunque genéticamente modificado por las teorías discursivas. Tantos métodos y procedimientos interpretativos puestos a «disposición» de los juristas, generan la objetivación de la interpretación, porque posibilitan al intérprete a sentirse excusado de mayores responsabilidades en la atribución de sentido, colocando en el fetichismo de la ley y en el legislador, la responsabilidad de las anomalías del derecho. Por eso es razonable afirmar que, en vista de la inexistencia de un «método fundamental», metamétodo o meta-criterio que sirva como «fundamento último» (especie de reconducción del fundamentum inconcussum absolutum veritatis) de todo el proceso hermenéutico interpretativo, el uso de los métodos es siempre arbitrario, propiciando interpretación ad-hoc, discrecionales. La imposibilidad de un Grundmethode constituye, así, el talón de Aquiles de la hermenéutica jurídica exegético-positivista. En este punto, por otra parte, reside el fuerte vínculo entre la hermenéutica metodológica y el positivismo jurídico, que de este modo se torna refractario al paradigma establecido por el neoconstitucionalismo. Resistente al giro hermenéutico ontológico, la hermenéutica jurídica viene posibilitando la sobrevivencia de las viejas tesis positivistas-normativistas acerca de la interpretación, como la subsunción, el silogismo, la individualización del derecho en la «norma-general» a partir de «criterios puramente cognitivos y lógicos», la libertad de conformación del legislador, la discrecionalidad del poder ejecutivo, tanto como la consideración de la Constitución como un estatuto destinado solo a reglamentar del ejercicio del poder.

Por tales razones, asume absoluta relevancia la ruptura paradigmática proporcionada por la hermenéutica filosófica, exactamente por la circunstancia de que la hermenéutica jurídica deja de ser una «cuestión de método» y pasa a ser filosofía. Consecuentemente, en la medida en que la filosofía no es lógica, la hermenéutica jurídica no puede ser solamente una herramienta para la organización del pensamiento. La hermenéutica posee una temática específica, dirá GADAMER. A pesar de su generalidad, no puede ser integrada legítimamente en la lógica. En cierto sentido, comparte con la lógica la universalidad. Mientras tanto, en otro sentido, la supera. Consiguientemente, en la hermenéutica filosófica, la herramienta no es decisiva, porque en el lenguaje existe algo que está más allá del enunciado, esto es, el enunciado no carga en sí mismo con el sentido, que vendría a ser «desacoplado» por el intérprete. En la interpretación siempre queda algo afuera, lo no dicho, lo inaccesible. Es así que «ser que puede ser comprendido es lenguaje», dirá GADAMER.

Tampoco se puede confundir la hermenéutica jurídica con las teorías de la argumentación jurídica o cualquier teoría lógico-analítica, las que poseen nítido carácter procedimental, tratándose, pues, de otra racionalidad, que es apenas racionalidad discursiva. La teoría de la argumentación jurídica —a pesar de que procure colocarse en confrontación con el positivismo-normativista - no superó el esquema representacional sujeto-objeto, porque continúa en la búsqueda de reglas previas (procedimientos) que puedan conformar deductivamente, las decisiones judiciales. Y esto no difiere de la metodología positivista.

En consecuencia, el comprender no depende de la institución de una «supervisión epistemológica» que sería realizada por las teorías del (y sobre el) discurso jurídico de tipo procedimental (en sus diversos matices). En verdad, tales teorías juegan 
como guardianes de una pretendida racionalidad instrumental, con lo que se torna razonable afirmar que una teoría de la argumentación jurídica puede ser válida sólo en aquello en que puede servir de auxilio en la justificación/explicitación del nivel de racionalidad comprensiva (estructurante del sentido, «como» hermenéutico) que, desde siempre, ya ha operado en el proceso interpretativo. Mientras que la hermenéutica filosófica trabaja en el nivel de un cómo hermenéutico-estructurante de la comprensión, que anticipa el sentido a partir del círculo hermenéutico, las teorías discursivas - en sus variadas formas- permanecen en el nivel de un cómo apofántico, axiomático-deductivo, de carácter lógico. Finalmente, comprensión y aplicación no acontecen en «etapas». Ellas simplemente coinciden. Aquí se sitúa la importancia de los argumentos basados en juicios de razonabilidad y de proporcionalidad, que son condición de posibilidad para cualquier interpretación. Por otra parte, GADAMER es taxativo al reconocer el hecho de que ese es el terreno que la hermenéutica jurídica comparte con la retórica: el terreno de los argumentos persuasivos y no de los argumentos lógicamente concluyentes.

\section{CONSIDERACIONES FINALES}

Hoy en día, en la era de las Constituciones compromisorias y sociales, en fin, en pleno pos-positivismo, una hermenéutica jurídica capaz de intermediar la tensión inexorable entre el texto y el sentido del texto, no puede seguir siendo entendida como una teoría ornamental del derecho, que sirva solamente para proveer «capas de sentido» a los textos jurídicos. Dentro de lo virtuoso del círculo hermenéutico, el comprender no ocurre por deducción. Consecuentemente, el método (el procedimiento discursivo) siempre llega tarde, porque presupone saberes teóricos separados de la «realidad». Antes de argumentar, el intérprete ya comprendió. La comprensión antecede, pues, a cualquier a argumentación. Ella es la condición de posibilidad. Por tanto, es equivocado afirmar, por ejemplo, que el juez, primero decide, para luego fundar; en verdad, él sólo decide porque ya encontró, en la anticipación del sentido, el fundamento (la justificación). Y solamente es posible comprender esto a partir de la admisión de la tesis de que el lenguaje no es un mero instrumento o «tercera cosa», interpuesta entre un sujeto (cognoscente) y un objeto (a conocer). El «abismo gnoseológico» que «separa» el hombre de las cosas y de la comprensión acerca de cómo ellas son, no depende —en el plano de la hermenéutica jurídico-filosófica - de puentes que vengan a ser construidos — paradojicamente- después de que la travesía (anticipación del sentido) ya ha sido hecha.

De ahí la importancia de la precomprensión, que pasa a ser condición de posibilidad en ese nuevo modo de mirar la hermenéutica jurídica. Nuestros prejuicios que conforman nuestra precomprensión, no son jamás arbitrarios. Los prejuicios no son inventados; ellos nos orientan en lo enmarañado de la tradición que puede ser auténtica o no auténtica. Pero esto no depende de la discrecionalidad del intérprete y tampoco de ningún control metodológico. El interprete no «domina» la tradición. Los sentidos que atribuirá al texto, no dependen de su voluntad, aunque así lo pretendan los adeptos del (metafísico) esquema representacional sujeto-objeto. El proceso unitario de la comprensión, por el cual interpretar es aplicar (applicatio) que desmitifica la tesis de 
que primero conozco, después interpreto y solo después aplico, se transforma en una especie de blindaje frente a las opiniones arbitrarias. La interpretación jamás se dará en abstracto, como si la ley (el texto) fuera un objeto cultural. Hay siempre, un proceso de concreción, que es la applicatio, momento del acontecer del sentido, que ocurre en la diferencia ontológica. No hay textos sin normas; no hay normas sin hechos. No hay interpretación sin relación social. Es en el caso que se atribuirá el sentido, que es único e irrepetible.

\section{BIBLIOGRAFÍA}

DwORKIn, R., 1985: A Matter of Principle, Cambridge: Harvard University Press.

- 1997: Los derechos en serio, Barcelona: Ariel.

- 2000: El Imperio de la Justicia, Barcelona: Gedisa.

EsSER, J., 1961: Principio y norma en la elaboración jurisprudencial del derecho privado, Barcelona: Bosch Casa Editorial.

GADAmER, H.-G., 1990: Wabrheit und Methode. Grundzüge einer philosophischen Hermeneutik. Tübingen: J. C. B. Mohr (Paul Siebeck).

- 1992: Verdad y Método II, 1986, trad. de M. OlasagasTi, Salamanca: Sígueme.

- 1993: Wabrbeit und Methode, Ergänzungen Register, Tübingen: J. C. B. Mohr (Paul Siebeck).

- 1999: Verdad y método. Fundamentos de una hermenéutica filosófica, 1975, trad. de A. Agud y R. DE AgAPITO, Salamanca: Sígueme.

- 2006: Hermenêutica em Retrospectiva. A Virada Hermenêutica, vol. II, Petrópolis: Vozes.

Grondin, J., 2000: Einführung zu Gadamer, Tübingen: J. C. B. Mohr (Paul Siebeck), 2000 (Introducción a Gadamer, trad. de C. RuIZ-GARRIDO, Madrid: Herder, 2003).

Heidegger, M., 1923: Hermenéutica de la Facticidad, trad. de M. Jiménez Redondo. Disponible en www.heideggeriana.com.ar/hermeneutica/indice.htm. Acceso el 27 de julio de 2007.

- 1993: Sein und Zeit, Siebzehnte Auflage, Tübingen, Max Niemayer, Verlag Tübingen (Ser e

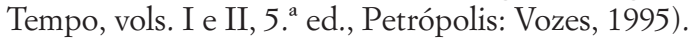

- 2005: Ser y tiempo, trad. de J. Eduardo Rivera, 4. a ed., Santiago: Editorial Universitaria.

Kaufmann, A., 1999: Filosofía del derecho, Bogotá: Universidad Externado de Colombia.

LAmego, J., 1990: Hermenêutica e Jurisprudência, Análise de uma «recepção», Lisboa: Fragmentos.

MüLLER, F., 1975: Recht-Sprache-Gewalt. Elemente einer Verfassungstheorie I, Berlin: Duncker \& Humblot.

- 1995: Direito Linguagem e Violência: elementos de uma teoria constitucional, trad. de P. NAUMANN, Porto Alegre: Sergio Antonio Fabris Editor, 1995.

- 2006: Métodos de trabajo del derecho constitucional, Madrid: Marcial Pons.

SCHAPP, I., 1985: Problemas fundamentais da metodologia jurídica, trad. de E. STEIN, Porto Alegre: Fabris.

SteIn, E., 2002: Pensar épensar a aferença. A filosofía e o conbecimento empitico, Iljui.

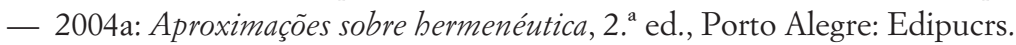

- 2004b: Exercícios de fenomenología, Ijui: Unijui.

- 2008: Racionalidade e existência: o ambiente bermenêutico e as ciências bumanas, 2. ${ }^{a}$ ed., Ijuí: Unijuí. 
STRECK, L. L., 2004: Jurisdição constitucionel e bermenêtica, 2. ${ }^{a}$ ed., Rio de Janeiro: Forense, cap. V.

- 2009a: Hermenêutica jurídica e(m) crise, 8. a ed., Porto Alegre: Livraria do Advogado.

- 2009b: Verdad y consenso, Lima: ARA.

- 2009c: Hermenéutica jurídica: estudios de teoría del derecho, Lima: ARA. 